\title{
An analysis of ethical awareness related to computers and information technology of people in the Bangkok metropolis
}

\author{
Pateep Methakunavudhi \\ Associate Professor, Faculty of Education, Chulalongkorn \\ University, Bangkok, 10330 Thailand \\ Phone: +66 2 2182690; Fax: +66 22153558 \\ Email:fedupmt@chulkn.car.chula.ac.th
}

\begin{abstract}
The objectives of this study were to analyze the ethical awareness of people in the Bangkok metropolis in relation to computers and information technology. The people were divided into three groups: computer professionals, customers, and students. Each of the three groups was further divided into three subgroups. Interviews were conducted with 358 people by using ten scenarios covering computer security principles. The study revealed that the ethical awareness among the groups was not different in eight of the ten scenarios. The groups considered the behaviours unethical in all scenarios on the issues of obligation and quality of the professional work; in all the scenarios on the issues of piracy and unauthorized access; in all the scenarios on the issues of intellectual property, contract, and business agreement; and only one scenario on the issues of confidentiality and privacy. However, the average percentages stating unethical behavior were not very high; they varied between $51-79 \%$. Two other scenarios on the issues of confidentiality and privacy were viewed as ethical behaviour, which was confirmed by Thai culture. The students' different educational levels created differences in ethical awareness and their responses. The variations in work experience of the computer professionals did not cause differences in ethical awareness.
\end{abstract}




\section{SYNTHESIZED VIEW OF THE RESEARCH}

\section{Research Rationale}

Computer systems raise many potentially serious social and ethical problems. In a society where information is a source of power, it is important to ask questions about who has access and who lacks access to information. To handle this, we need strict controls on who can do what with private information about any individual in the society. Data protection and information privacy are of everincreasing importance with the advancement of technology in communications. Privacy in information systems requires a different approach from those found among the strictly technically-oriented approaches. Technical professionals often focus largely on improving the stage of technology without considering the ends to which that technology is applied. However, there is a growing interest in understanding the social and ethical implications of technology. Some professional groups have been concerned with these issues and have pointed out that, when we design new technological systems, we should also ask what is ethically desirable as well as what is technically feasible. If codes of ethics and professional conduct in the age of technology are used, technology may be controlled and redirected towards achieving positive human and environmental values.

The concepts of ethical and legal issues in relation to computers vary in different societies and have been very well developed in the western countries. In Thailand, there are few concerns among the people or among public and private organizations about ethics and legislation related to computer and information privacy. However, from a business point of view, there is a need to change attitudes if Thailand wants to become an equal participant in the global world market. Increasing interaction in the world market, international markets such as the European common market and the Organization for Economic Cooperation and Development (OECD), calls for critical concerns and movements in relation to information technology, business, customers, and citizens.

Prior to proposing great changes in any legislation, the positive approach is to convince people. It is a humane way to start with demands from the users and laypeople. Wise and good decisions concerned with information technology cannot be made unless people know and understand reality. Thus, the findings from this research on people's awareness will reveal significant points for future changes in the use of information technology in Thailand.

\section{Objectives}

The objectives of this research were as follows:

- to survey people's ethical awareness related to computers and information technology, and

- to analyze people's ethical awareness according to Thai culture and towards the Association for Computing Machinery (ACM) Code of Ethics and Professional Conduct. 


\section{Research Framework}

In accordance with the research questions specification stated above, the research framework was designed as follows.

Table 1. The Research Framework

\begin{tabular}{|c|c|c|}
\hline Objectives & Sample and Instruments & Analyses \\
\hline $\begin{array}{l}\text { 1. To survey } \\
\text { people's ethical } \\
\text { awareness related } \\
\text { to computer and } \\
\text { information } \\
\text { technology. } \\
\text { 2. To analyze } \\
\text { people's ethical } \\
\text { awareness } \\
\text { according to Thai } \\
\text { culture and } \\
\text { towards the ACM } \\
\text { Code of Ethics and } \\
\text { Professional } \\
\text { Conduct. }\end{array}$ & $\begin{array}{l}\text { Scenario interviews of three } \\
\text { main groups } \\
\text { of people: } \\
\text { a) computer professionals ( } 3 \\
\text { subgroups) } \\
\text { - administrators of computer } \\
\text { centres/offices, } \\
\text { - instructors on IT } \\
\text { programmes, } \\
\text { - project leaders/system } \\
\text { engineering/system } \\
\text { programmers/database } \\
\text { administrators/etc. } \\
\text { b) consumers as users ( } 3 \\
\text { subgroups) } \\
\text { - users with at least a } \\
\text { bachelor's degree } \\
\text { and whose work related to } \\
\text { law, } \\
\text { - users with at least a } \\
\text { bachelor's degree in any } \\
\text { area, } \\
\text { - users with secondary and } \\
\text { elementary education. } \\
\text { c) students as young } \\
\text { generations ( } 3 \text { subgroups) } \\
\text { - students on bachelor's } \\
\text { degree programmes in IT, } \\
\text { - students on bachelor's } \\
\text { degree programmes in any } \\
\text { area, } \\
\text { - students in } \\
\text { elementary/secondary } \\
\text { schools. }\end{array}$ & $\begin{array}{l}\text { 1. Comparison of } \\
\text { opinions: } \\
\text { - within groups } \\
\text { - between groups } \\
\text { 2. Comparison of } \\
\text { opinions with Thai } \\
\text { culture and with the } \\
\text { ACM Code of } \\
\text { Ethics and } \\
\text { Professional } \\
\text { Conduct }\end{array}$ \\
\hline
\end{tabular}


The specific questions were as follows:

1. What was the ethical awareness related to computer and information technology among the groups of people with different backgrounds such as computer professionals, consumers, and students?

2. Did the work experiences of persons who had used computers or any machines related to data or information storage or transmission affect their ethical awareness?

3. Did the levels of education of the young generations (the students) affect their ethical awareness?

4. What was the analysis of the ethical awareness according to Thai culture and towards the ACM Code of Ethics and Professional Conduct?

\section{METHODOLOGY}

\section{The Scenarios Development}

Reviewing related materials led to the development of scenarios as a research instrument. The scenario method was chosen as a technology assessment analysis which systematizes the nature, importance, impacts, and advantages. This assessment can trace, formulate, and develop socially desirable and useful technological applications (Berleur, 1993). The scenarios were created by using a three-dimensional framework: Dimension 1 - Issues, which included security, privacy, quality of work, use of service and contract; Dimension 2 - Environment, which included academic, business, government, and hospital environments; and Dimension 3 - Object, which included physical property, intellectual property, and financial assets. Firstly, thirty-two scenarios were created. After reviewing the scenarios context, ten scenarios were selected (for the full text of the ten scenarios, see Appendix B) and were classified into a three-dimensional framework.

Table 2. Composition of the Scenarios

\begin{tabular}{lrlrlr}
\hline Issue & Scenario & Object & Scenario & Environment & Scenario \\
\hline Privacy & 3 & Database & 5 & Government & 3 \\
Confidentiality & 2 & Software & 3 & Business & 3 \\
Quality of professional & & Hardware and software 1 & Academic & 2 \\
work & 2 & & & \\
Unauthorized access & 1 & Intellectual property & 1 & Independent & 2 \\
Use of service & 1 & & & & \\
Contract & 1 & & & \\
\hline
\end{tabular}

\section{The Sample of Scenario Interviews}

The stratified sample of three groups of people in Bangkok was selected for the scenario interviews by using three criteria showed in summary table as follows: 
Table 3. The Sample Groups for the Scenario Interviews

\begin{tabular}{llll}
\hline Group of sample & Subgroup 1 & Subgroup 2 & Subgroup 3 \\
\hline $\begin{array}{l}\text { Computer } \\
\text { Professionals }\end{array}$ & Administrators of & Instructors on IT & Project leaders, \\
(N=118) & computer centres & programmes & etc. \\
Consumers (users) & $(50)$ & $(23)$ & $(45)$ \\
& whose work & at least a & secondary/elem- \\
$(N=150)$ & related to law & bachelor's degree & entary education \\
Students & $(30)$ & $(60)$ & $(60)$ \\
(Young & bachelor's & bachelor's & secondary/elem- \\
generations) & programmes & programmes & entary education \\
(N=90) & $($ IT area) & (any area) & \\
\hline
\end{tabular}

In total, the sample in the scenario interviews was 358 persons. The sample in each subgroup was selected by using the following combination:

- Computer professionals, subgroups 1 and 3, were selected from persons in different working areas such as in banks/finance/stocks/insurance companies, hospitals, government/semi-government offices, Social Security Office, Civil Registration Office, and the Office of the Narcotics Control Board. Subgroup 2 consisted of instructors on computer science/IT programmes in public and private universities.

- Consumer subgroup 1 was selected from persons whose work related to law such as police officers, lawyers, judges, senators, representatives, and persons who worked at the Office of the Council of State. Other subgroups were selected from people with different educational backgrounds who were working and who did not work.

- Student subgroups were selected from public and private universities and schools.

\section{The Scenario Analyses}

In order to analyze people's awareness from their responses to the scenario interviews according to the stated objectives 1 and 2 , three steps were taken: 1) analysis according to the affective domain within 2 levels (level 1- acknowledge, and level 2 - opinion/reaction) (Krathwohl, et al., 1956); 2) analysis according to Thai culture (belief, values, and ways of living); and 3) analysis according to the ACM Code of Ethics and Professional Conduct (ACM, 1993) (see also Appendix A). 


\section{RESULTS}

\section{Findings of Question No. 1}

Table 4. Percentage Comparison of the Responses between Computer Professionals, Consumers, and Students towards the Issue: Obligation and Quality of Professional Work

\begin{tabular}{llllllllllllll}
\hline Group & \multicolumn{3}{l}{$\begin{array}{l}\text { Professionals } \\
(n=118)\end{array}$} & \multicolumn{3}{l}{$\begin{array}{l}\text { Consumers } \\
(n=150)\end{array}$} & \multicolumn{3}{l}{$\begin{array}{l}\text { Students } \\
(n=90)\end{array}$} & \multicolumn{4}{c}{$\begin{array}{l}\text { Average } \\
(n=358)\end{array}$} \\
Scenario & 2 & 5 & 9 & 2 & 5 & 9 & 2 & 5 & 9 & 2 & 5 & 9 \\
\hline Ethics & 51 & 25 & 25 & 48 & 31 & 36 & 43 & 25 & 37 & 47 & 27 & 32 \\
Unethics & 47 & 73 & 74 & 50 & 68 & 64 & 56 & 74 & 63 & 51 & 71 & 67 \\
No Response & 2 & 2 & 1 & & 2 & 1 & - & 1 & 1 & - & 2 & 2 & 1 \\
\hline
\end{tabular}

More than $50 \%$ of the computer professionals considered scenario 2 ethical, but fewer than $50 \%$ of the consumers and students considered it was unethical. Reasons for considering it ethical were that the application programs had already been accepted by users as stated in a contract, and the application programs could be implemented even though there were some problems which should be resolved later. The reasons it was considered unethical included that the application programs could not be used according to the users' needs; and the computer company should have taken responsibility for the effective application programs development even though the programs had already been accepted by users.

In scenarios 5 and 9 , more than $50 \%$ of all groups believed that the persons acted unethically. Scenario 5 dealt with the project leader who implemented the company design but handed in the chief officer's design documents in order to please him. The respondents considered the project leader acted unethically because the documentation did not match the implementation, and because he delivered an unmaintainable system. In Scenario 9, a system programmer who used his office computer to do his personal work during the weekend was considered unethical because he used official resources for personal benefit, and he used them without permission.

Table 5. Percentage Comparison of Responses between Computer Professionals, Consumers, and Students towards the Issue: Piracy and Unauthorized Access

\begin{tabular}{|c|c|c|c|c|c|c|c|c|c|c|c|c|}
\hline \multirow{2}{*}{$\begin{array}{l}\text { Group } \\
\text { Scenario }\end{array}$} & \multicolumn{3}{|c|}{$\begin{array}{l}\text { Professionals } \\
(n=118)\end{array}$} & \multicolumn{3}{|c|}{$\begin{array}{l}\text { Consumers } \\
(n=150)\end{array}$} & \multicolumn{3}{|c|}{$\begin{array}{l}\text { Students } \\
(n=90)\end{array}$} & \multicolumn{3}{|c|}{$\begin{array}{l}\text { Average } \\
(n=358)\end{array}$} \\
\hline & 1 & 6 & 7 & 1 & 6 & 7 & 1 & 6 & 7 & 1 & 6 & 7 \\
\hline Ethics & 38 & 20 & 43 & 30 & 34 & 36 & 25 & 23 & 37 & 31 & 25 & 34 \\
\hline Unethics & 61 & 79 & 55 & 70 & 66 & 64 & 75 & 77 & 73 & 68 & 74 & 65 \\
\hline No response & 1 & 1 & 2 & - & . & - & - & 1 & - & 1 & 1 & 1 \\
\hline
\end{tabular}


Regarding piracy and unauthorized access (Table 5), the majority of the responses from the three groups considered persons in scenarios 1,6 , and 7 acted unethically. In scenario 1, a system programmer dealt with confidential data concerning an individual with alcohol and drug problems. He brought the data home from work and left it at home. He acted unethically because the data was a confidential government document and disclosure of the data would be dangerous. In scenario 6, the participants considered a scientist's action unethical because he did not give informed consent to subjects and he did not ask for the university's permission to use the data. In scenario 7 , a bank was involved in a joint project with a department store involving customers' information. The participants believed the act was unethical because it violated customers' privacy, used personal data for other objectives, and disclosed customers' personal data without permission.

Table 6. Percentage Comparison of Responses between Computer Professionals, Consumers, and Students towards the Issue: Confidentiality and Privacy

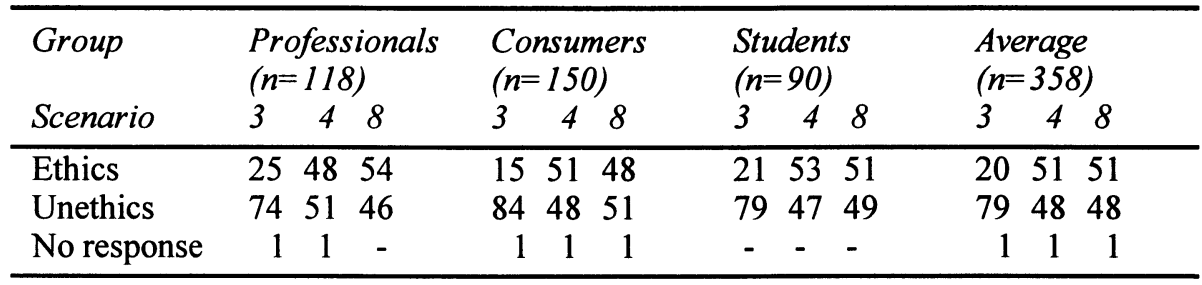

On the issue of confidentiality and privacy in scenario 3 , as seen in Table 6 , every group of participants agreed that a company administrator's behaviour in reading employees' email was unethical. However, their opinions differed in scenario 4 , which was about using multimedia in neurosurgery at a teaching hospital. The professional group viewed it as unethical whereas the consumers and the students concurred that the hospital acted ethically. The professionals did not agree very strongly that the hospital violated patients' privacy. The consumers and the students considered the activity was an efficient use of technology for medical education. In scenario 8 , only the consumers stated that the life insurance company acted unethically in violating personal privacy by storing HIV/AIDS tests in the customers' database. However, the professionals and the students contended that the company had policies and procedures for data security and that the data were important medical records for life insurance.

As far as intellectual property, contract, and business agreements are concerned (Table 7), a large majority of the participants considered the programmer's behaviour in developing a new application program from an existing product was unethical. Such developments, they insisted, violated copyright law. The programmer had to ask for permission to apply the designs and had to honour the intellectual property of others. 
Table 7. Percentage Comparison of Responses between Computer Professionals, Consumers, and Students towards the Issue: Intellectual Property, Contract, and Business Agreement

\begin{tabular}{llcllllll}
\hline Group & \multicolumn{2}{l}{$\begin{array}{l}\text { Professionals } \\
(n=118)\end{array}$} & \multicolumn{2}{l}{ Consumers } & \multicolumn{2}{l}{$\begin{array}{l}\text { Students } \\
(n=150)\end{array}$} & \multicolumn{2}{c}{$\begin{array}{l}\text { Average } \\
(n=90)\end{array}$} \\
Scenario & 5 & 10 & 5 & 10 & 5 & 10 & 5 & 10 \\
\hline Ethics & 25 & 21 & 31 & 25 & 25 & 15 & 27 & 20 \\
Unethics & 73 & 78 & 68 & 75 & 74 & 85 & 71 & 79 \\
No response & 2 & 1 & 1 & - & 1 & - & 2 & 1 \\
\hline
\end{tabular}

\section{Findings of Question No. 2}

The percentage comparison of ethical and unethical acts between computer professionals with experience equal to or more than 5 years $(n=10)$, fewer than 5 years $(n=35)$, and information technology students $(n=30)$ was not much different from the findings to question no. 1 except in scenario 2 where the group of computer professionals who had fewer than 5 years' experience did not judge that the computer company action was ethical or unethical in submitting the inefficient application programs to the customers. They stated that the company acted $50 \%$ ethically and $50 \%$ unethically. Thus, the findings concluded that the work experiences of persons who had used computers or any machines related to data or information storage or transaction did not affect their ethical awareness.

\section{Findings of Question No. 3}

The percentage comparison of ethical or unethical acts between bachelor's degree programme students in information technology $(n=30)$ and in other areas $(n=30)$, and secondary and elementary school students $(n=30)$ was different. The responses to the issues revealed that, in scenario 2 , only the secondary and elementary students stated that the computer company acted ethically. They could not determine whether the programmer who accessed all the files and copied them to do work at home (scenario 1) showed ethical or unethical behavior. Their responses were $50 \%$ of ethics and unethics. In the confidentiality and privacy issue (scenario 4 and 8), elementary and secondary school students and bachelor's degree students in other areas concurred that the hospital and the insurance company acted ethically. Thus, it might be concluded that their responses showed how they perceived ethical issues of information technology. Their responses, for example, were as follows:

- scenario 1 : ethical behaviour because the programmer did not intend to do it;

- scenario 2 : ethical behaviour because the computer company did nothing wrong;

- scenario 3 : ethical behaviour because the administrator did the right thing;

- scenario 6 : ethical behaviour because the researcher asked his friend to do it; and 
- scenario 7 : unethical behaviour because the bank should not attach commercial advertisements.

Thus, the findings could reveal that the educational levels of the young generations did affect their ethical awareness.

A summary table of ethical awareness related to computer and information from the sample groups with different backgrounds; the sample groups with different lengths of experience; and the sample groups with different levels of education are shown in Table 8.

Table 8. Summary of Ethical Awareness Related to Computers and Information Technology of People in the Bangkok Metropolis

\begin{tabular}{|c|c|c|c|c|c|c|c|c|}
\hline \multirow{2}{*}{$\begin{array}{l}\text { Comparison } \\
\text { Between }\end{array}$} & \multicolumn{2}{|c|}{$\begin{array}{l}\text { Issue no.1 } \\
\text { ethics/uneth. }\end{array}$} & \multicolumn{2}{|c|}{$\begin{array}{l}\text { Issue no. } 2 \\
\text { ethics/uneth. }\end{array}$} & \multicolumn{2}{|c|}{$\begin{array}{l}\text { Issue no. } 3 \\
\text { ethics/uneth. }\end{array}$} & \multicolumn{2}{|c|}{$\begin{array}{l}\text { Issue no.4 } \\
\text { ethics/uneth }\end{array}$} \\
\hline & $2,5,9$ & - & $1,6,7$ & - & 3 & 4,8 & 5,10 & - \\
\hline \multicolumn{9}{|l|}{ Within Group } \\
\hline $\begin{array}{l}\text { Comp. } \\
\text { professionals }\end{array}$ & 5,9 & 2 & 6,7 & 1 & 3 & 4,8 & 5,10 & - \\
\hline Consumers & 5,9 & 2 & 1 & $6,7^{*}$ & 3 & 4,8 & 5,10 & - \\
\hline Students & 5 & $2,9^{*}$ & $1,6,7$ & - & 3 & 4,8 & 5,10 & - \\
\hline Experiences & 5,9 & 2 & $1,6,7$ & - & 3 & $4 *, 8$ & 5,10 & - \\
\hline Education & 5 & 2,9 & 6,7 & 1 & 3 & $4^{*}, 8$ & 5,10 & - \\
\hline
\end{tabular}

* Percentage response was $50 \%$ of ethical and $50 \%$ unethical behaviour

Note:

Issue no.1 : Obligation and Quality of Professional Work

Issue no.2 : Piracy and Unauthorized Access

Issue no.3 : Confidentiality and Privacy

Issue no.4 : Intellectual Property, Contract, and Business Agreement

Ethics/uneth.: Response was ethical or unethical behaviour

Nos. 1-10: The scenario number

\section{Findings of Question No. 4}

The analysis of people's ethical awareness according to Thai culture derived from the sample's responses. Normally, Thai culture is very traditional. People are brought up in a traditional way and are very friendly to others. They are taught to respect their ancestors, parents, and leaders. They are grateful and devout. Thus, the group of school students, who did not have much computer or information technology knowledge, reacted ethically or unethically according to tradition as stated in their responses (see Findings of Question No. 3). Generally speaking, Thais are not sensitive to privacy issues. Perhaps this comes from a long tradition of close cooperation which is necessary for rice cultivation. In this way, Thai behaviour has been formed not on the basis of respect for original individuality but for orderly human relations based on community social strata. Behaviour has been formulated according to the relations between subordinate and superior, young and 
old, husband and wife, parent and child, among colleagues, and among relatives. Such behaviour also remains today in the bureaucratic societies of large companies and administrative organizations. It is also the cause of the ambiguous Thai attitude towards decision-making: for example, Thais do not say no clearly. They do not wish to hurt others by giving a definite no to those who have asked them a question. Since Thais have become more involved internationally and come in contact with other cultures, this kind of communication and way of decisionmaking has changed. So, it can be said that there are now two types of cultures of people in Thailand: those who are very sensitive to privacy and those who are not. This difference could be seen by the participants' responses to the ethical awareness of scenarios 3,4 , and 8 .

The analysis of people's ethical awareness towards the ACM Code of Ethics and Professional Conduct shows that the participants' responses in scenario 1, for example, could be classified according to the principles in the ACM Code, 1.7, 1.8 , and 2.8, which were described as respect for the privacy of others, honouring confidentiality, and accessing computing and communication resources only when authorized to do so. Other scenario responses could be classified according to other principles.

\section{CONCLUSIONS AND SUGGESTIONS}

\section{Conclusions}

1. The ethical awareness related to computer and information technology among the groups of people with backgrounds as computer professionals, consumers, and students was not different in eight of the ten scenarios. The groups considered the behaviour unethical in all scenarios related to issues of obligation and quality of professional work (scenario 2, 5, 9); all scenarios on the issues of piracy and unauthorized access (scenario 1, 6, 7); all scenarios on the issues of intellectual property, contract, and business agreement (scenario $5,10)$; and only one scenario in the issue of confidentiality and privacy (scenario 3). For the other scenarios, the responses varied. However, the average percentages stating unethical behaviour were not very high: in scenarios 2,5 , and 9 , they were $51 \%, 71 \%$, and $67 \%$; in scenarios $1,6,7$, they were $68 \%, 74 \%$, and $65 \%$ respectively; and $79 \%$ in scenarios 3 and 10 .

2. The variations in work experience of the computer professionals who had used computers or any machines related to data or information storage and transmission for 5 years or more than 5 years, fewer than 5 years, and students did not cause differences in ethical awareness.

3. The different educational levels of students (young generation): IT bachelor's degree programme students; other bachelor's degree programme students; secondary school students; and elementary school students created differences in ethical awareness and their responses.

4. The analysis of sample responses showed different opinions or reasons according to various points of view related to work experience. These did not include the consumer groups who did not work and the elementary and secondary school student groups. The school students used their common 
sense in responding to the scenarios. However, most of the sample's opinions were based on Thai culture. One significant finding was that two of the three scenarios (4 and 8 ), relating to confidentiality and privacy, were viewed as ethical behaviour, which was confirmed by Thai culture.

5. Most of the sample's responses concurred with the ACM Code of Ethics and Professional Conduct. However, there were sample groups mentioned above whose responses were different.

\section{Suggestions}

From the findings, there are some suggestions for further development in ethical awareness related to computers and information technology in Thailand:

1. Computer Ethics Education. Basic ethical values are learned in the formative years of childhood at home, church, and school. Computer ethics education is made more complicated because there are computer users at all levels throughout the society. Computer ethics education should not indoctrinate the individual with new values but assist individuals in clarifying and applying their ethical values. As technology assumes an integral role in education, institutions in the electronic community of learners should train and support faculty, staff, and students to use information technology effectively. This could include the skills to use the resources, to be aware of the existence of data repositories, and to understand the ethical and legal use of the resources (Connolly, 1993). At any level of curriculum and instruction, there should be an integration of both general and specific approaches to computer ethics and social impact issues. The general approach is to incorporate these concerns across the curriculum and instruction.

2. Computer Code of Ethics and Professional Conduct. During the last few years, the International Federation for Information Processing (IFIP) set up an Ethics Task Group. The Ethics Task Group undertook a survey of codes of ethics in four major areas of ethics: individual professional ethics, multinational organizational ethics, international legal informatics ethics, and international public policy ethics. They analyzed codes from the IFIP national societies, IFIP affiliate members (regional societies), and other computer societies. From the survey, the responsibility field is of course the most developed part within the codes. Five main categories appear as regrouping the different wordings adopted by the different societies: respectful general attitude, personal/institutional qualities, promotion of information privacy, production and flow of information, and regulations (Berleur, 1996). This movement should be a sign that there is a need for the computer society in Thailand to work on this issue and propose solutions which will really protect society as well as the public and the computer profession.

3. IFIP recommends treating with care the distinction between Codes of Ethics and Codes of Conduct. It appeared in the analysis and in the comments that the first are more often oriented towards the public and society, while the second seem to be related more to the computing profession. Codes of ethics could be seen as mission statements of computer societies, providing visions and objectives in relation to their public mission and anticipating the issues in a computerized world or in an information society. Codes of Conduct would 
have to deal with issues in the specialized fields of the profession (Berleur, 1996).

4. Computer Laws. International guidelines may provide statements which act as reference documents or as a basis for the development of legal instruments in particular jurisdictions. Legal instruments are generally the most enforceable, provided they are drafted correctly and the courts are sufficiently qualified to assess the matter brought before them. Ethical principles, codes, guidelines, and policies may anticipate and supplement the law (Berleur and Brunnstein, 1996). In Thailand, the need for international standards of a computer code of ethics and professional conduct and computer laws should be considered for the near future, for example, computer crime laws, privacy law, data protection law, telecommunication law, and electronic data interchange law (Methakunavudhi and Pethsiri, 1996). There is a belief that legislation is the best method of enforcing ethics and also that a code of ethics can enforce a set of rules.

5. Recommendation for Further Research. The research recommendation based on the findings of this research is for an analysis of university policies, organizational policies, and public policies regarding codes of ethics in information processing. It is known that other organizations have also stated a process of reassessing their role about ethical issues. The analysis of university policies should include curriculum and instruction analysis. Although some more specific fields seem to be covered by the universities and their policies, an ethical preoccupation does not appear explicitly in the wording at least as a specific statement. The comparison of university policies with computer societies codes could be quite interesting.

\section{REFERENCES}

ACM Code of Ethics and Professional Conduct, Communication of the ACM 36(2) (February, 1993): 99-105.

Anderson, Ronald E. et al., Using the New ACM Code of Ethics in Decision Making, Communication of The ACM 36 (2) (February, 1993): 98-107.

Berleur, Jacques. What is happening now with technology assessment? In: Beardon, Colin and Whitehouse Diane. (Eds.) Computers and Society. Oxford: Intellect Books Publishing, 1993.

Berleur, Jacques. International Federation for Information Processing's Framework for Computer Ethics. Science and Engineering Ethics. 2 (2), 1996, pp. 155-165.

Berleur, J. and K. Brunnstein. (Ed.), Ethics of Computing: Codes, Spaces for Discussion and Law. London: Chapman \& Hall, 1996.

Clement, Andrew. Privacy Considerations in CSCW: Report on the CSCW92 Workshop, SIGCHI BULLETIN 25 (4) (October, 1993): 34-41.

Connolly, F. W. A Bill of Rights and Responsibilities for Electronic Learners, Published Paper, 1993.

Krathwohl D.R., Bloom, B.S., and Masia, B.B. Taxonomy of Education Objectives: The Classification of Educational Goals. Handbook II: Affective Domain New York: David McKay, 1956.

Methakunavudhi, Pateep and Pethsiri, Apirat. A Guideline for Data Protection and Information Privacy Legislations in Thailand. The Office of National Research Commission, Thailand 1996.

$\mathrm{Oz}$, Effy. Ethical Standards for Information Systems Professionals: A Case for a Unified Code, MIS Quarterly 16 (4) (December 1992): 423-433.

Oz, Effy. When Professional Standards are Lax: The CONFIRM Failure and Its Lessons, Communications of The ACM 37 (10) (October 1994): 29-36. 
Parker, Don B. Ethical Conflicts in Information and Computer Science, Technology and Business Massachusetts : QED Information Science, Inc., 1990.

Schwarz, Heinrich. Multimedia Technology and Privacy: A Case in Neurosurgery, ACM SIGOIS Bulletin 4 (1) (July, 1993): 19-20.

\section{APPENDIX A}

\section{The Suggested Comparison with the ACM Code of Ethics and Professional Conduct}

The ACM code of ethics and professional conduct can be classified in each scenario as follows:

\section{Scenario 1}

No. 1.7 Respect the privacy of others.

No. 1.8 Honour confidentiality.

No. 2.8 Access computing and communication resources only when authorized to do so.

\section{Scenario 2}

No. 2.1 Strive to achieve the highest quality effectiveness and dignity in both the process and product of professional work.

No. 2.4 Accept and provide appropriate professional review.

No. 3.2 Manage personnel and resources to design and build information systems that enhance the quality of working life.

No. 3.4 Ensure that users and those who will be affected by a system have their needs clearly articulated during the assessment and design of requirements. Later the system must be validated to meet requirements.

\section{Scenario 3}

No. 1.7 Respect the privacy of others.

No. 3.2 Manage personnel and resources to design and build information systems that enhance the quality of working life.

\section{Scenario 4}

No. 1.2 Avoid harm to others.

No. 1.7 Respect the privacy of others.

No. 1.8 Honour confidentiality.

\section{Scenario 5}

No. 1.3 Be honest and trustworthy.

No. 2.5 Give comprehensive and through evaluations of computer systems and their impacts, including analysis of possible risks.

No. 2.6 Honour contracts, agreements and assigned responsibilities.

\section{Scenario 6}

No. 1.5 Honour property rights.

No. $2.3 \mathrm{Know}$ and respect existing laws pertaining to professional work.

No. 2.8 Access computer and communication resources only when authorized to do so.

\section{Scenario 7}

No. 1.7 Respect the privacy of others.

No. 1.8 Honour confidentiality.

No. 3.3 Acknowledge and support proper and authorized uses of an organization computing and communication resources.

No. 3.5 Articulate and support policies that protect the dignity of users and others affected by a computing system. 


\title{
Scenario 8
}

No. 1.2 Avoid harm to others.

No. 1.7 Respect the privacy of others.

No. 3.5 Articulate and support policies that protect the dignity of users and others affected by a computing system.

\section{Scenario 9}

No. 1.3 Be honest and trustworthy.

No. 2.3 Know and respect existing laws pertaining to professional work.

No. 2.8 Access computer and communication resources only when authorized to do so.

\section{Scenario 10}

No. 1.5 Honour property rights including copyrights and patents.

No. 1.6 Give proper credit for intellectual property.

No. 2.6 Honour contracts, agreements and assigned responsibilities.

No. 2.8 Access computer and communication resources only when authorized to do so.

\section{APPENDIX B}

\begin{abstract}
Scenario 1
Thanachai worked in a large state department of alcoholism and drug abuse. The agency administered programmes for individuals with alcohol and drug problems, and maintained a huge database of information on the clients who used their service. Some of the data files contained the names and current addresses of clients. Thanachai had been asked to take a look at the track records of the treatment programmes. He had to put together a report that contained a number of clients seen in each programme and each month for the past five years, with details of the length of the client's treatment, the number of clients who returned after completion of a programme, criminal histories of clients, and so on. In order to put together this report, Thanachai had been given access to all the files in the agency's mainframe computer. After assembling the data into a new'file that included the client names, he downloaded it to the computer in his office. Under pressure to get the report finished by the deadline, Thanachai decided he had to work at home over the weekend in order to finish on time. He copied the information onto several disks and took them home. After finishing the report he left the disks at home and forgot about them. (Adapted from Anderson et al., 1993.) Thanachai's behaviours are ethical or unethical according to professional conduct in computing?
\end{abstract}

\section{Scenario 2}

A computer company was writing the first stage of a more efficient accounting system that would be used by the government. This system would save taxpayers a considerable amount of money every year. A computer professional, who was asked to design the accounting system, assigned different parts of the system to her staff. One person was responsible for developing the reports; another was responsible for the internal processing; and a third for the user interface. The manager was shown the system and agreed that it could do everything in the requirements. The system was installed but the staff found the interface so difficult to use that their complaints were heard by upper-level management. Because of these complaints, upper-level management would not invest any more money in the development of the new accounting system and they went back to using the original, inefficient system. (Adapted from Anderson et al., 1993.) The computer company's behaviours are ethical or unethical according to professional conduct in computing?

\section{Scenario 3}

When Ratana arrived for work at a company one morning, she discovered her supervisor reading and printing out electronic mail messages between other employees. As electronic mail administrator, Ratana was appalled. When she had trained employees to use the computerized system, Ratana had told them their mail was private. Now the company manager was violating that trust. When Ratana questioned the practice, she was told to mind her own business. A day later, she was fired for insubordination. She still bristled about the company for the reason that the company administrators did not read people's mail, just as they did not listen to people's phone conversations. However, the administrators disagreed completely. 'If the corporation owns the equipment and pays 
for the network, that asset belongs to the company and it has a right to look and see if people are using if for purposes other than running the business,' they said. (Adapted from Clement, 1993.) The company administrators' behaviours are ethical or unethical according to professional conduct in computing?

\begin{abstract}
Scenario 4
Multimedia technology can facilitate communication particularly in situations where people do not share time and space. It does that by taking information out of its original context and presenting it in a different one. Video and audio were used to support neurophysiological monitoring during neurosurgery in a teaching hospital. The video image was the view of the operating field through the microscope. This image was also displayed on a television monitor in the operating room to give other people in the operating room information about the progress of the operation and the surgical activities. The audio comprised everything that was picked up by a small microphone attached to the microscope: sound from the surgical procedures, voice, and other sounds from the room. When video and audio transmission were first introduced, there was little objection. But a year later, when it was going to be used more regularly, criticism about the practice became loud, leading to a wider discussion and open resistance. The reasons for the criticisms were concerns about legal implications, job control issues, impacts on teaching, the flow of conversations, and the patients' privacy. (Adapted from Oz, 1994.) The procedures at the hospital are ethical or unethical according to professional conduct in computing?
\end{abstract}

\title{
Scenario 5
}

Surapol worked in a computer consultancy and, as a skilful software tester, he had carefully designed a computer system to manage dangerous material for the navy. His design was rejected by a chief officer who was in charge of the project. The chief officer wanted his own design substituted for Surapol's design. Surapol believed that the chief officer's design was untestable. The chief officer said to do it this way or the project would be abandoned. Surapol sought advice but there was a deadline for this project, so he had to make a decision. He went to the chief officer and said that he would implement the chief officer's design. After a few months, the system was completed. The system passed its acceptance tests. The chief officer, with a self-congratulatory tone, told the other officers how he had helped Surapol's design. Surapol too was satisfied. He knew the system would pass the tests because he had implemented the system in the way he had originally designed. Although Surapol's documentation of the system made it look like the chief officer's design had been used, the code did not follow the chief officer's untestable design. The design documentation did not match the implemented code. (Adapted from Clement, 1993.) Surapol's behaviour is ethical or unethical according to professional conduct in computing?

\section{Scenario 6}

Nikom was a scientist employed by a university as a researcher. He learned that two different kinds of data on essentially the same subject were contained in two files stored in the university's computer. He believed that there would be significant scientific value in merging the files and reanalyzing the data. Although the subjects' informed consent had been obtained for the earlier studies, their permission for this new use of the data had not been sought. Nikom was aware that it would be desirable to seek permission for use of the data, but he decided not to do so, because it would be time-consuming and would add considerably to the cost of the study he was proposing. He thus asked one of the university's programmers to access the data, merge the files on the same subjects, and analyze the data as he indicated. The programmer did as he requested. (Adapted from $\mathrm{Oz}$, 1992.) Nikom's behaviour is ethical or unethical according to professional conduct in computing?

\section{Scenario 7}

A department store cooperated with a bank in arranging a credit card for their customers, and the bank stored the customers' information in their computer. Every month the bank chose some of the current or prospective customers for particular offers of products or services. The use of existing customer information such as name, address, and appending additional data elements of demographic information relating to its customers such as estimated income, dwelling size, propensity to use credit, and so forth, was also done at the bank. The bank submitted the computer tape with this information to outside vendors who had connections with the bank. These were used, in turn, to target customers for various product offerings, either via mail or sometimes using inserts in 
customers' bills. The customers began to complain about marketing practices. (Adapted from Parker, 1990.) The bank's behaviour is ethical or unethical according to professional conduct in computing?

\section{Scenario 8}

A life insurance underwriting process entailed the gathering of medical information regarding each applicant for life insurance so that, based on the individual's health risk, the application could be accepted or rejected and, if accepted, the appropriate premium could be calculated. When testing for the AIDS virus became available, the life insurance company wished to include those tests in the underwriting process, store the results in the databases, and share the results with other life insurance companies through the Medical Information Bureau. After the life insurance companies began performing AIDS tests, they had to confront the issue of negative public and legislative reaction to the collection of AIDS tests information. (Adapted from Parker, 1990.) The life insurance companies' behaviors are ethical or unethical according to professional conduct in computing?

\section{Scenario 9}

Nakorn worked as a systems analyst in a government office. In the workplace, his job was usually not busy, so he could spend some time doing his own extra work. He used the computer service at his workplace early in the morning, after office hours, late at night, and even during the weekend to develop programs. His colleagues, however, explicitly stated that the government office's computer was not to be used for personal benefit and they sent a notice to the administrators. (Adapted from $\mathrm{Oz}$, 1992.) Nakorn's behaviour is ethical or unethical according to professional conduct in computing?

\section{Scenario 10}

A system programmer in a computer company, Akachai, was assigned to do a systems design project for a commercial company. While he was working there, he learned that there was an interesting application software which was used in this company and it was not included in his project. He realized that he could produce a new package that would be faster, have greater capacity, and offer additional features. He also concluded that other commercial companies could be users of this package if he could produce it. Then he offered the manager of the commercial company to add to his project by using the program modification. When his work was completed, the manager of the commercial company was satisfied with the package without knowing that Akachai had sold the package to other commercial companies. (Adapted from Oz, 1992.) Akachai's behaviour is ethical or unethical according to professional conduct in computing? 